\title{
Development of a model of Saint Louis encephalitis infection and disease in mice
}

Rafael Elias Marques ${ }^{1,7^{*}}$ D, Juliana L. Del Sarto ${ }^{1 \dagger}$, Rebeca P. F. Rocha ${ }^{1 \dagger}$, Giovanni F. Gomes ${ }^{2}$, Allysson Cramer $^{3}$, Milene A. Rachid ${ }^{4}$, Danielle G. Souza ${ }^{5}$, Maurício L. Nogueira ${ }^{6}$ and Mauro M. Teixeira ${ }^{1}$

\begin{abstract}
Background: Flaviviruses are a genre of closely related viral pathogens which emerged in the last decades in Brazil and in the world. Saint (St.) Louis encephalitis virus (SLEV) is a neglected flavivirus that can cause a severe neurological disease that may lead to death or sequelae. St. Louis encephalitis pathogenesis is poorly understood, which hinders the development of specific treatment or vaccine.

Methods: To address this problem, we developed a model of SLEV infection in mice to study mechanisms involved in the pathogenesis of severe disease. The model consists in the intracranial inoculation of the SLEV strain BeH 355964, a strain isolated from a symptomatic human patient in Brazil, in adult immunocompetent mice.

Results: Inoculated mice presented SLEV replication in the brain, accompanied by tissue damage, disease signs, and mortality approximately 7 days post infection. Infection was characterized by the production of proinflammatory cytokines and interferons and by leukocyte recruitment to the brain, composed mainly by neutrophils and lymphocytes. In vitro experiments indicated that SLEV is able to replicate in both neurons and glia and caused neuronal death and cytokine production, respectively.

Conclusions: Altogether, intracranial SLEV infection leads to meningoencephalitis in mice, recapitulating several aspects of St. Louis encephalitis in humans. Our study indicates that the central nervous system (CNS) inflammation is a major component of SLEV-induced disease. This model may be useful to identify mechanisms of disease pathogenesis or resistance to SLEV infection.
\end{abstract}

Keywords: St. Louis encephalitis, SLEV, Mouse model, Viral encephalitis, Inflammation

\section{Background}

St. Louis encephalitis virus (SLEV) is a causative agent of encephalitis in humans and horses in the Americas [1-3]. SLEV is a member of the Flavivirus genus, together with important human pathogens, such as Dengue and Zika viruses, but belongs to the Japanese encephalitis virus (JEV) serocomplex [4]. Like all flaviviruses, SLEV is a single-stranded positive-sense RNA virus, with a genome of approximately $11 \mathrm{~kb}$ that encodes three structural genes and seven non-structural

\footnotetext{
* Correspondence: rafael.marques@Inbio.cnpem.br

${ }^{\dagger}$ Equal contributors

${ }^{1}$ Immunopharmacology, Departamento de Bioquímica e Imunologia, Instituto de Ciências Biológicas, Universidade Federal de Minas Gerais, Belo Horizonte, Minas Gerais, Brazil

${ }^{7}$ Present address: Laboratório Nacional de Biociências, Centro Nacional de

Pesquisa em Energia e Materiais, Campinas, São Paulo, Brazil

Full list of author information is available at the end of the article
}

genes [5]. SLEV transmission cycles involve Culex mosquitoes, birds, and a variety of mammals [3], although alternative cycles involving other mosquito species have been reported [6]. SLEV is closely related to JEV and West Nile virus (WNV), both also characterized by the ability to cause severe neurological disease in humans $[7,8]$. The recent emergence of Zika virus (ZIKV) and the prospect of outbreaks of other flaviviruses indicates how necessary it is to study neglected arboviral diseases [6,9].

The majority of SLEV infections in humans is asymptomatic or result in flu-like or dengue-like symptoms [10-12]. Severe cases are acute and characterized by intense headache, fever, and neurological alterations such as confusion, convulsions, loss of body reflexes, paralysis, meningitis, and/or encephalitis [13-16]. Mortality rates in severe cases may reach $20 \%$, and 
survivors often present with neurological sequelae, such as cognitive impairment, memory loss, and incoordination $[17,18]$. There are no specific treatments or a vaccine available against St. Louis encephalitis, although prototype vaccines were developed and shown to protect mice against SLEV challenge [19-21].

The development of specific treatments against SLEV infection would benefit from a greater understanding of disease pathogenesis, which is limited and mostly inferred from the study of other flaviviral infections. From this perspective, rodent models represent an important and extensively used tool for the study of flaviviral encephalitis $[15,22,23]$. The earliest reports of experimental SLEV infection in mice were performed in the early 1930s, following SLEV discovery, and consistently described the ability of SLEV to cause brain damage and death $[13,22,24]$. Based on mortality indexes and seroconversion, mouse models of SLEV infection were used to characterize the virulence of SLEV isolates [25], to assess vaccine efficacy [19-21], and to test potential treatments [26, 27]. Moreover, mechanisms leading to SLEV invasion of the central nervous system (CNS), a critical step in the pathogenesis of viral encephalitis, were studied using a hamster model of infection [28]. Overall, factors such as age, route of inoculation, and the viral strain are determinant for mouse and hamster susceptibility to SLEV infection [29].

In this manuscript, we describe a robust model of SLEV infection in $\mathrm{C} 57 \mathrm{BL} / 6 \mathrm{~J}$ and $\mathrm{Balb} / \mathrm{c}$ mice that recapitulates several aspects of human disease [13]. This experimental model is based on the intracranial inoculation of a SLEV strain isolated from a symptomatic patient in Brazil $[5,30]$ into adult immunocompetent mice, which develop severe neurological disease. We found that SLEV replicates in the brains of infected mice, causing the production of proinflammatory cytokines and the recruitment and activation of leukocytes, which is consistent with meningoencephalitis. SLEV infection causes significant brain damage and results in death. Importantly, this study indicates that CNS inflammation is a major component of SLEV-induced disease.

\section{Methods}

\section{Mice}

Eight- to 12-week-old wild type (WT) C57BL/6 or Balb/c mice were purchased from Centro de Bioterismo of UFMG (Belo Horizonte, Brazil). All animals were kept in the laboratory animal facility under controlled temperature $\left(23{ }^{\circ} \mathrm{C}\right)$ with a strict 12 -h light/dark cycle, food, and water available ad libitum. All experimental procedures were approved by and complied with the regulations of Universidade Federal de Minas Gerais (UFMG) Committee for Ethics in Animal Use (CEUA), under protocol number 349/2012.

\section{Virus}

SLEV strain BeH 355964 was provided by Prof. Luis Tadeu Moraes Figueiredo (Universidade de São Paulo, SP, Brazil). BeH 355964 stocks were generated by passage in C6/36 mosquito cell monolayers, cultivated in Leibovitz-15 supplemented with $10 \% v / v$ fetal bovine serum (FBS) (Cultilab, Brazil) and antibiotics. Clarified supernatants containing virus were titrated by plaque assay in Vero cells, and viral titers were expressed in plaque forming units (PFU)/mL of supernatant. SLEV $\mathrm{BeH} 355964$ complete genome sequence is available at GenBank under accession number KM267635 [5].

\section{In vivo experimental infection}

Mice were inoculated intracranially (i.c.) or intraperitoneally (i.p.) with different inocula of SLEV or saline, as mock-infected control. Inocula were prepared by diluting viral stocks (as L-15 clarified supernatants) in saline. Viral dilutions in saline were at least 1000-fold, resulting in a solution that contained negligible amounts of the original L-15 culture supernatant. Injected volumes were 20 and $100 \mu \mathrm{L}$ for i.c. and i.p. routes, respectively. For the i.c. inoculation, mice were anesthetized using Isoflurane (Biochimico, Brazil) 5\% v/v inhalation. A syringe containing the inoculum was positioned perpendicularly to the head on the intersections of medial and sagittal planes, following insertion of the needle into the cranial cavity, injection and perpendicular removal from within the cranial cavity. Mice were observed twice a day for 14 days or up to determined time points for sample collection, at which mice were anesthetized with ketamine/xylazine (Syntec, Brazil) before collection of blood and organs, or euthanized by $\mathrm{CO}_{2}$ inhalation. All tissue samples were stored at $-80{ }^{\circ} \mathrm{C}$ until analysis. On survival experiments, mice presenting with severe disease signs (such as complete paralysis) were euthanized by $\mathrm{CO}_{2}$ inhalation and considered dead in data analysis.

\section{Quantification of viral load}

SLEV load in cell culture and tissue samples was determined by plaque assay and/or reverse transcriptase quantitative PCR (RT-qPCR). Tissue samples were processed into $10 \% w / v$ homogenates in DMEM prior to analysis by both techniques. Briefly, the plaque assay consisted in the serial dilution of samples for adsorption in Vero cell monolayers, for an hour. Samples were removed, following the addition of an overlay media containing $1.5 \% \mathrm{w} / \mathrm{v}$ carboxymethylcellulose (Synth, SP, Brazil) in $2 \%$ fetal bovine serum (FBS) $v / v$ DMEM. After 7 days, plates were fixed with formaldehyde, washed and stained with methylene blue (Synth, SP, Brazil) 1\% $w / v$. Results were expressed as plaque forming units (PFU)/mL of supernatant or PFU/100 mg of tissue. For the RT-qPCR reaction, samples were submitted to RNA extraction 
(QIAamp viral RNA extraction kit, QIAgen) and cDNA synthesis using random primers (Promega) and SuperScript Reverse Transcriptase III (Invitrogen), according to the companies' specifications. The qPCR reaction was performed in the 7500 Fast platform using SYBR green reagents (Applied Biosystems) and primers targeting SLEV NS5 gene (primer forward FG1 TCAAGGAACTCCACA CATGAGATGTACT, primer reverse nSLE ATTCTT CTCTC AATCTCCGT), as described elsewhere [31]. All PCR reactions were accompanied by a standard curve of the 232 bp NS5 amplicon. Results were expressed as relative number of genome copies of SLEV per sample.

\section{Quantification of cytokines and chemokines}

Concentrations of Interferon (IFN) $\gamma$, CCL5, CXCL-1, IL-6, IL-1 $\beta$, IL-10, IL-17, and TNF- $\alpha$ were quantified in cell culture or processed tissue samples by ELISA (R\&D Systems, USA), following the manufacturer instructions. The detection limit of quantitative ELISA was in the range of 4-8 pg/mL or picogram per $100 \mathrm{mg}$ of tissue. Results are expressed as picogram per $100 \mathrm{mg}$ of tissue, picogram per milliliter of supernatant or by absorbance at $490 \mathrm{~nm}$. Type I IFN (IFN $\alpha$ and IFN $\beta$ ) levels were determined in processed samples by RT-qPCR using specific primers (IDT, USA). Cycle threshold (Ct) values of target genes were normalized to the housekeeping gene $18 \mathrm{~S}$ and analyzed according to the $\Delta \Delta \mathrm{Ct}$

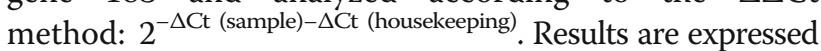
as fold increase over the mock-infected WT group.

\section{Determination of enzymatic activity from leukocytes}

Assays to detect the activity of myeloperoxidase (MPO), eosinophil peroxidase (EPO), and $N$-acetil- $\beta$-D-glucosaminidase (NAG) were performed in tissue samples as a measure of leukocyte recruitment into target organs. To measure MPO and EPO activity, tissue homogenates were prepared in $1 \mathrm{~mL}$ of PBS containing $0.5 \%$ hexadecyltrimethyl ammonium bromide (HTAB) and $5 \mathrm{mM}$ EDTA. Saline/ Triton X-100 $0.1 \% v / v$ was used to process tissues for NAG activity measurement. Test protocols were performed as already described [32]. Briefly, samples were evaluated for their ability to convert the substrates $p$-nitrophenyl- $\beta$-glycosamine (for NAG), 3,3' 5,5' tetramethylbenzidine (for MPO) or $o$-phenylenediamine (for EPO) to generate a colored solution proportional to the amount of enzyme in the sample. Plates for each assay were read at 405, 450, and $495 \mathrm{~nm}$, respectively, and results expressed as absorbance.

\section{Hematological parameters}

Blood was collected from the brachial plexus of anesthetized mice in heparinized tubes for total and differential leukocyte count, platelet count, measurement of the hematocrit index, and, separately, for serum. Platelets and leukocytes were quantified in an optical microscope (Zeiss ICS Standard 25) using a Neubauer chamber or mounted microscope slides, containing Diff-quik-stained samples (Laboclin, Brazil). The hematocrit index was determined on centrifuged blood samples in heparinized glass capillaries. Results are as counts $/ \mathrm{mm}^{3}$, per milliliter of blood (leukocytes), or percentage (hematocrit).

\section{Flow cytometry}

Mice were euthanized and perfused with $15 \mathrm{~mL}$ of PBS. The brains were collected, homogenized individually, and centrifuged against Percoll gradients (35 and 70\%) for separation of leukocytes/microglia. Collected cells were washed, counted, and stained with antibodies against leukocyte surface markers (CD3, CD4, CD8, CD19, CD69, GR-1, F4/80, NK1.1) (all purchased from BD Biosciences). Cells were fixed in buffered $4 \% v / v$ formaldehyde and acquired in a FACS Canto II cytometer (BD Biosciences). Analyzed cell populations included lymphocytes, granulocytes, and macrophages/microglia, initially gated by size/ granularity and subsequently by the expression of surface markers, and compared to negative and isotype-stained controls. Data were analyzed using FlowJo (Tree Star), and results expressed as total cell number of positive cells per brain/animal.

\section{Histopathology}

Mice were euthanized and perfused with $15 \mathrm{~mL}$ of PBS and $15 \mathrm{~mL}$ of buffered $4 \% v / v$ formaldehyde, for the collection of brains. Sections ( $5 \mu \mathrm{m}$ thick) were made in a rostral to caudal fashion, mounted and stained in H\&E. Sections were then analyzed for signs of brain pathology and inflammation, focusing on the regions of the hippocampus and the cortex/meninges. Images were obtained at $\times 200-400$ magnification using an Olympus BX51 optical microscope equipped with a camera.

\section{Behavioral assessment}

Behavioral changes induced in mice by SLEV infection were first assessed using the SHIRPA battery of tests [33]. Briefly, mice are submitted to 40 quick tests individually, observed and evaluated semi-quantitatively on their performance. The SHIRPA battery was performed in the laboratory animal facility, and results were expressed as a score for each animal in experimental groups. Mice were also assessed for alterations on the spontaneous locomotor activity, using the open-field method. Mice are placed individually in a transparent acrylic cage for $20 \mathrm{~min}$. Their movement was recorded with a video camera and analyzed for total traveled distance, using the software Any-Maze (Stoelting Company). Results are expressed as traveled distance per mouse in a given experimental group. 


\section{In vitro experimental infections}

N1E-115 mouse neuroblast cell line was kindly provided by Josiane Piedade (FUNED, Belo Horizonte, Brazil) and maintained in DMEM supplemented with $5 \mathrm{mM}$ HEPES, $10 \% v / v$ SFB, and antibiotics. Primary neuronal cell cultures were obtained from the cortex and striatum areas of C57BL/6 embryos at 15 days post coitum. After dissection, the tissue was digested with trypsin and dissociated. Cells were plated into poli-L-ornitine-coated plaques with Neurobasal medium supplemented with 2nM Glutamax, B-27, and antibiotics (all purchased from Gibco, Thermo Fisher Scientific, USA). Cell cultures were incubated in $37{ }^{\circ} \mathrm{C}$ at $5 \% \mathrm{CO}_{2}$ for $5-7$ days until use. Primary mixed glia cultures were obtained by collecting the brains of newborn mice (1-2 days old). Brains were minced and digested in $0.1 \% \mathrm{w} / \mathrm{v}$ trypsin (Gibco) for 15 min under agitation. Brain homogenates were washed in DMEM twice and plated in cell culture flasks containing DMEM supplemented with 10\% FBS. Mixed glial cell cultures were harvested after 9-14 days. Briefly, cell cultures were infected with SLEV at a MOI of 0.1 for $1 \mathrm{~h}$, washed in DMEM and incubated at $37{ }^{\circ} \mathrm{C} 5 \%$ $\mathrm{CO}_{2}$ until sample collection (24-96 h post infection). Collected samples included cell culture supernatants for measurement of cytokine levels and viral load. Neuronal death was assessed in primary cultures using the LIVE/DEAD Viability/Cytotoxicity kit for mammalian cells (Molecular probes, Thermo Fisher Scientific, USA) and observed using a FLoid Cell imaging station (Life Technologies).

\section{Statistical analysis}

Results are expressed as mean plus standard error of mean, unless otherwise stated. Raw data were first analyzed for the presence of outliers (GraphPad quickCalcs) and checked for Gaussian distribution. Data sets were compared using ANOVA, followed by Tukey or Sidak post-tests. Differences between survival curves were analyzed using the log-rank test. Results with $P<0.05$ were considered significant. All data are representative of at least two experiments $(n=4$ to $n=12$ replicates or $n=7$ to $n=17$ mice).

\section{Results}

Wild-type adult mice are susceptible to intracranial inoculation of SLEV BeH 355964 in an inoculum-dependent manner

Our studies were initiated by the inoculation of SLEV $\mathrm{BeH}$ 355964, henceforth referred to as SLEV, in adult (8-12 weeks) wild-type (WT) BALB/c mice. Mice were inoculated with $10^{5} \mathrm{PFU}$ of SLEV via the intraperitoneal (i.p.) or intracranial (i.c.) routes and followed for signs of disease and mortality for 14 days (Fig. 1a). The majority of mice inoculated with SLEV via the i.c. route presented disease signs such as ruffled fur and hunched back at 6 to 7 days after infection (p.i.), which developed into complete paralysis and death. Mice inoculated with SLEV via the i.p. route or injected with saline (Fig. 1a, Mock i.c., Mock i.p.) did not present with disease signs or death. We also performed an experiment in which mice were inoculated with SLEV via intraplantar or subcutaneous (s.c.) routes, in addition to i.p. and i.c. routes already tested. We observed that mice infected by peripheral routes (intraplantar, s.c. and i.p.) did not present disease signs or mortality, whereas mice inoculated with SLEV via the i.c. route manifested disease and mortality at 6-7 days p.i. (Additional file 1: Figure S1).

To investigate if SLEV-induced mortality was inoculumdependent, we infected groups of BALB/c (Fig. 1b) with different inocula of SLEV and followed for signs of disease and need for euthanasia. This experiment was performed in parallel with other commonly used laboratory mouse strains (SV129, Fig. 1c) (C57BL/6, Fig. 1d) to test SLEV infection reproducibility. Infected mice of all strains manifested severe disease and death in an inoculum-dependent fashion, although strains had different degrees of susceptibility to SLEV infection. SV129 mice (Fig. 1c) were found to be more resistant to SLEV i.c. infection, followed by BALB/c mice (Fig. 1b) and finally by the more susceptible C57BL/6 mice (Fig. 1d). All mock-infected mice (injected with saline) had no disease signs. In order to minimize variation and inconsistencies, only female mice were used in the following experiments.

Our data indicate that SLEV can cause disease and death in immunocompetent mice when injected directly into the CNS but not when injected systemically. SLEV-induced disease and mortality were inoculum-dependent and reproducible across different commonly used mouse strains.

\section{SLEV infects and replicates in mice brains}

In order to characterize the disease induced by the i.c. injection of SLEV in mice and ultimately the events leading to death in this model, we inoculated female adult C57BL/ 6 mice intracranially with $10^{3}$ PFU of SLEV. This inoculum was selected as it was equivalent to a lethal dose $\left(\mathrm{LD}_{100}\right)$ of SLEV in C57BL/6 mice (Fig. 1d). Mice were euthanized for sample collection at days 3, 5, and 7 after infection, in time points that precede and include the peak of mortality observed in previous experiments. Brain samples were collected, processed, and assessed for viral load by plaque assay (Fig. 2a) and RT-qPCR (Fig. 2b). Our results indicated that the number of plaque forming units (PFU) and SLEV genome copies increase exponentially in the brains of infected mice during the evaluated time points (Fig. 2a, b), which are both undetectable in mockinfected controls. SLEV accumulation in the brain peaked at day 7 p.i., as indicated by both techniques. Thus, our results indicate that, upon i.c. inoculation, SLEV infects and replicates in the mouse brain. 

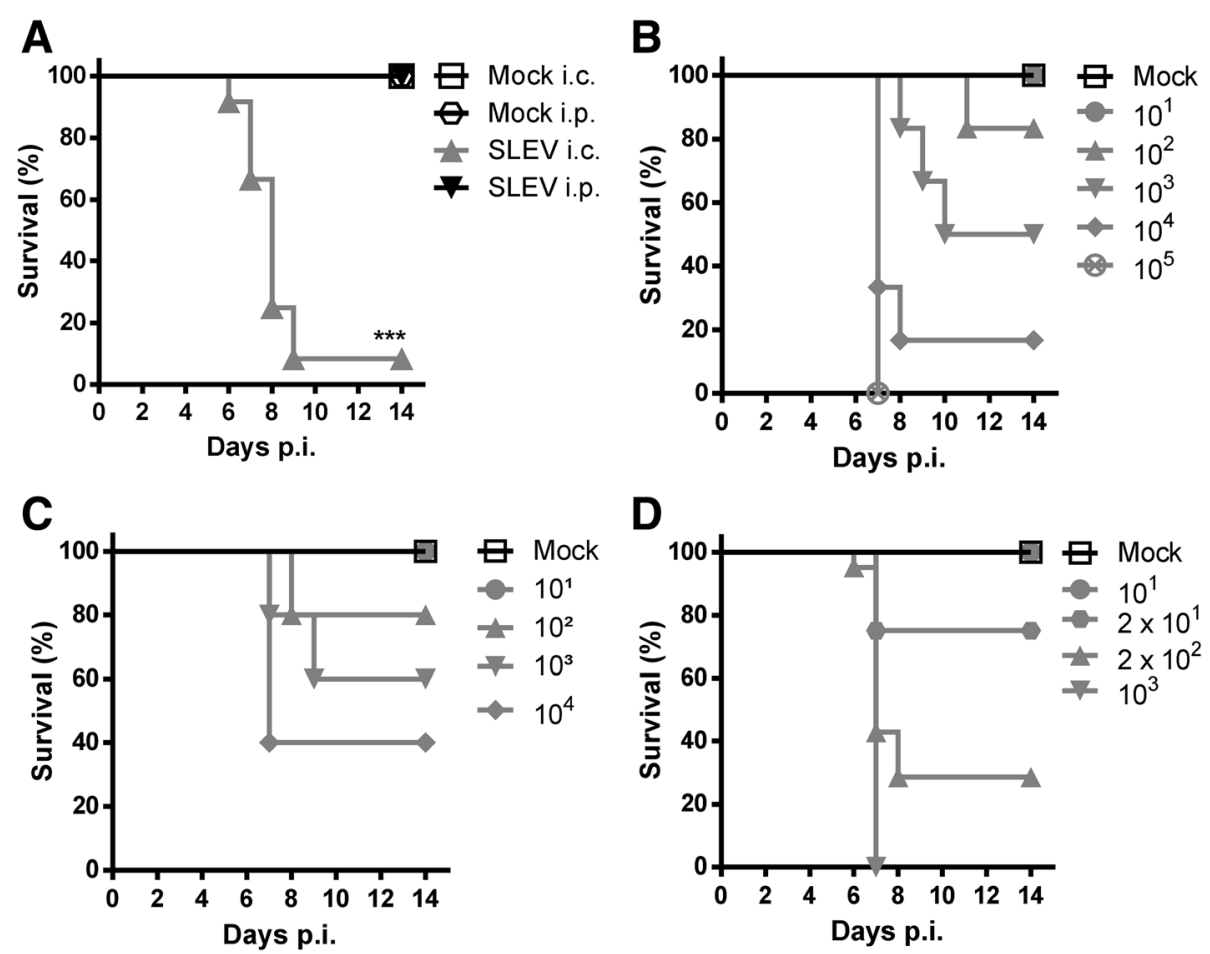

Fig. 1 Intracranial inoculation of SLEV BeH 355964 causes disease and mortality in adult wild-type mice in an inoculum-dependent manner. a Eight- to 12-week-old BALB/C mice were inoculated intracranially (i.c.) or intraperitoneally (i.p.) with $10^{5}$ PFU of SLEV BeH 355964 and observed for 14 days post infection (p.i.). b, c, d Eight- to 12-week-old BALB/c (b), SV129 (c), and C57BL/6 (d) were infected i.c. with different inocula of SLEV BeH 355964 and observed for 14 days p.i.. Results are expressed as percentage of survival in each group and are representative of two experiments. Mock $=$ injected with saline. $N=6-9$ mice. ${ }^{* * *} P<0.001$ compared to the respective Mock-infected group

SLEV infection induces the production of proinflammatory cytokines and interferons in the mouse brain

SLEV replication in the brain was accompanied by the local production of cytokines, chemokines, and interferons (IFNs). Tissue samples from mock-infected and SLEV-
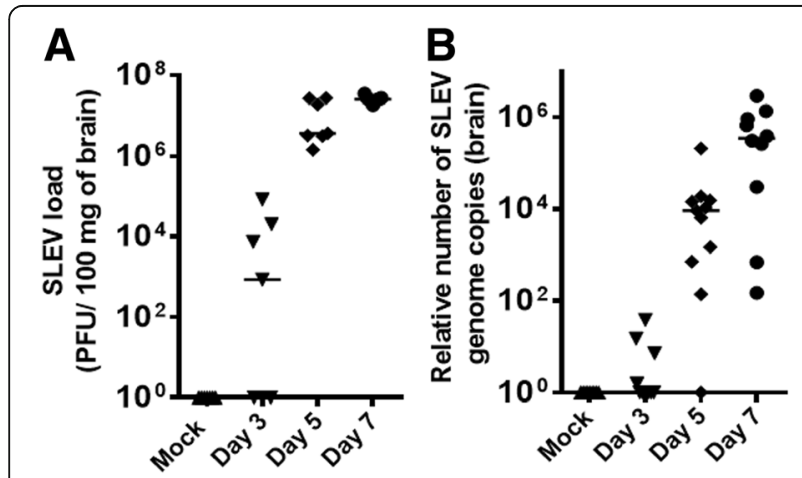

Fig. 2 SLEV infects and replicates in the brains of mice. Adult female C57BL/6 mice were inoculated i.c. with $1 \mathrm{LD}_{100}$ of SLEV and euthanized at days 3, 5, and 7 p.i. for brain collection. Viral load in brains was measured by plaque assay (a) and by RT-qPCR (b). Results are expressed as a PFU/100 mg of brain or $\mathbf{b}$ relative number of SLEV genome copies, including the median for each experiment group. Mock $=$ injected with saline infected mice euthanized at days 3, 5, and 7 p.i. were collected, processed, and assessed by ELISA or by RT-qPCR (Fig. 3). The choice of cytokines was based on the known role of these molecules in the context of neuropathology, either by mediating inflammation (IL-6, IL-1 $\beta$, TNF $\alpha$, CCL5, CXCL1) and/or by their association to viral infections (IFNs). All cytokines measured were increased in infected brains as infection progressed to day 7 p.i., when compared to levels observed in the mock-infected group. The cytokines IL-6 (Fig. 3a), CCL5 (Fig. 3d), and CXCL1 (Fig. 3e) were already increased in the brains of SLEVinfected mice at day 5 p.i. In contrast to IL-6, levels of CCL5 and CXCL1 continued to increase and reached peak levels at day 7 p.i.. The cytokines IL-1 $\beta$ (Fig. 3b), TNF $\alpha$ (Fig. 3c), and IFNs (Fig. 3f, g, h) were increased only at day 7 p.i.. In summary, SLEV replication in the brain is associated to the expression of proinflammatory cytokines and IFNs, which reached peak levels at day 7 p.i.

\section{SLEV infection leads to the recruitment of lymphocytes and neutrophils into the brain of the infected mice} The observation that SLEV caused the production of chemokines led us to investigate whether there would be influx of circulating leukocytes into the brain after infection. Blood samples collected from mice inoculated with 

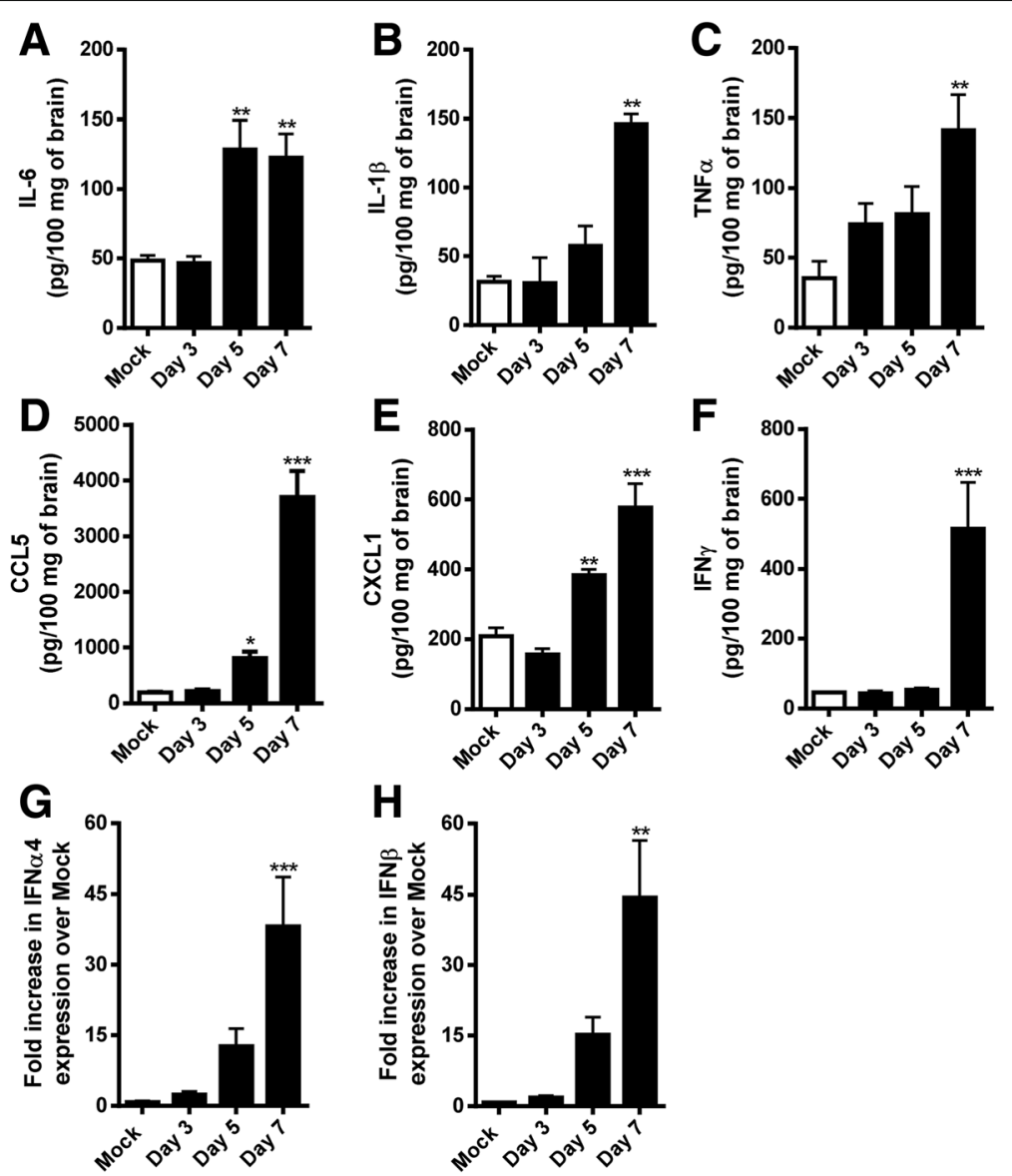

Fig. 3 SLEV infection induces the production of cytokines and interferons in the brain of mice. Adult female C57BL/6 mice were inoculated i.c. with $1 \mathrm{LD}_{100}$ of SLEV and euthanized at days 3, 5, and 7 p.i. for brain collection. Levels of the cytokines IL-6 (a), IL-1 $\beta$ (b), TNF-a (c), CCL5 (d), CXCL1 (e), and IFN- $\gamma(\mathbf{f})$ were quantified by ELISA in 10\% w/V brain homogenates. IFNa4 $(\mathbf{g})$ and IFN $\beta$ (h) levels were quantified by RT-qPCR in RNA extractions from brain samples. The limit of detection of the test is $4-8 \mathrm{pg} / \mathrm{mL}$. Results are expressed as mean plus standard error of the mean (SEM) and are representative of two independent experiments $(N=7-14) .{ }^{*} P<0.05,{ }^{* *} P<0.01,{ }^{* *} P<0.001$ compared to the respective Mock-infected group. Mock = injected with saline

saline (Mock) or $1 \mathrm{LD}_{100}$ of i.c. inoculated SLEV, at days 3,5 , and 7 p.i., were used for total and differential counting of leukocytes (Fig. 4a, b). Our results showed that SLEV-infected mice present reduced numbers of circulating leukocytes already at day 3 p.i., which is maintained during day 5 and further reduced at day 7 p.i. (Fig. 4a). The differential leukocyte count showed that the leukopenia presented by infected mice was due to lymphopenia, as infected mice had a significant decrease in lymphocyte numbers at all time points evaluated, when compared to uninfected controls (Mock) (Fig. 4b). In addition to leukocyte counts, blood samples were also evaluated for platelet counts and for the hematocrit index. SLEV infection could not alter the numbers of platelets or the hematocrit index, which remained similar to levels presented by salineinjected controls (Mock) (Additional file 2: Figure S2).

To continue our analysis, brain homogenates from infected and control mice were tested for the presence of infiltrating leukocytes through detection of the enzymatic activity of MPO, NAG, and EPO, present in neutrophils, macrophages, and eosinophils, respectively (Fig. 4c, d, e). Our results showed an increase in MPO activity (Fig. 4c) and a minor increase in EPO activity (Fig. 4e) in the brains of SLEV-infected mice at day 7 p.i., relative to the respective Mock controls. No differences were observed for the activity of NAG in mock and SLEV-infected groups (Fig. 4e). These data indicate that neutrophils, and to lesser extent eosinophils, are recruited to SLEV-infected mice brains.

In order to confirm our previous results and to investigate the recruitment of lymphocytes in SLEV in vivo infection, flow cytometry experiments were performed (Fig. 5). Groups of mice were injected with saline i.c. or inoculated i.c. with $1 \mathrm{LD}_{100}$ of SLEV. Brains were perfused, collected at days 5 and 7 p.i., and processed for the isolation of leukocytes. Recovered cells were composed mainly of neutrophils and lymphocytes (Fig. 5a) and increased in number as infection progressed (Fig. 5b). Neutrophils were the most prevalent leukocyte 


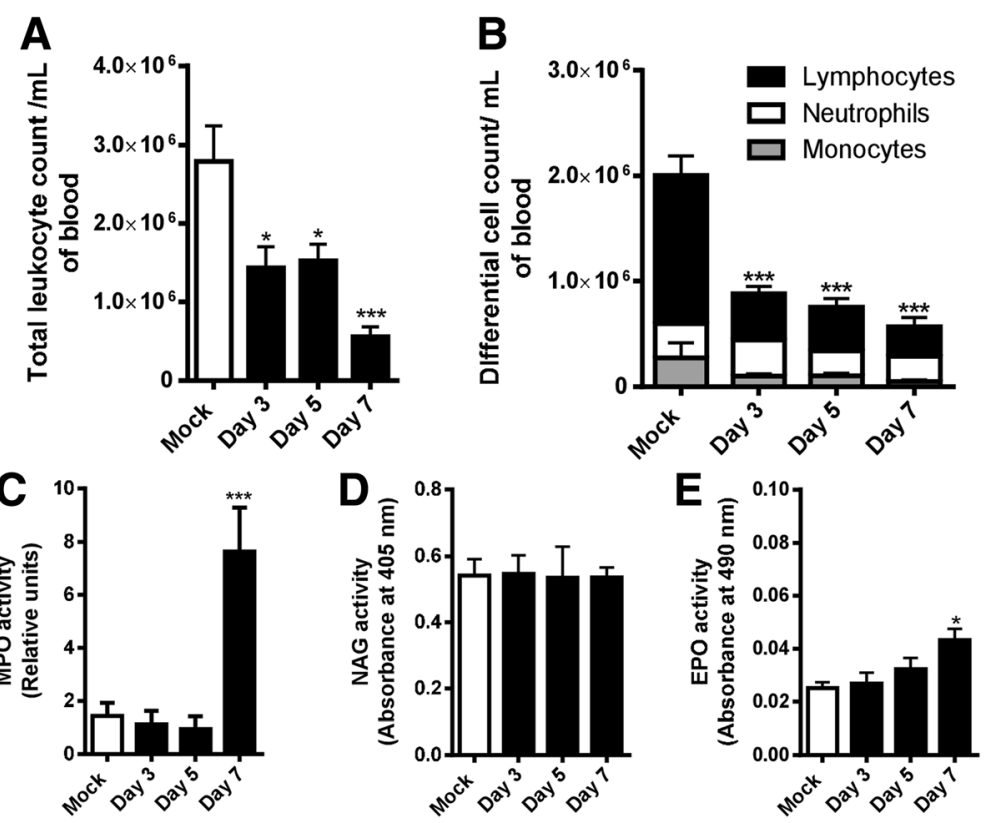

Fig. 4 SLEV infection causes leukopenia characterized by lymphopenia in mice and causes the recruitment of granulocytes to the brain. Adult female C57BL/6 mice were inoculated i.c. with $1 \mathrm{LD}_{100}$ of SLEV and euthanized at days 3, 5, and 7 p.i. for collection of blood and brain. Blood samples were used for total (a) and differential (b) leukocyte counts. Brain samples were processed and used in assays for detection of enzymatic activity of MPO (c), NAG (d) and EPO (e). Results are expressed as mean plus standard error of the mean (SEM) and are representative of two independent experiments $(N=6-15) .{ }^{*} P<0.05,{ }^{* * *} P<0.001$ compared to the respective Mock-infected group. Mock $=$ injected with saline
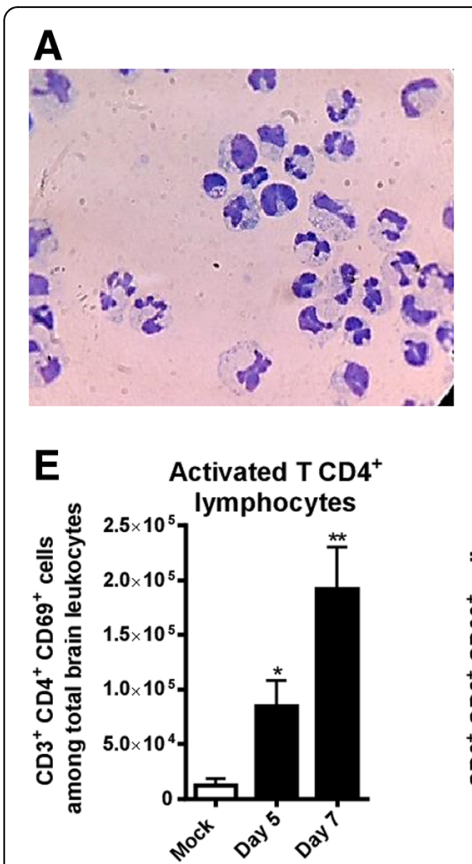

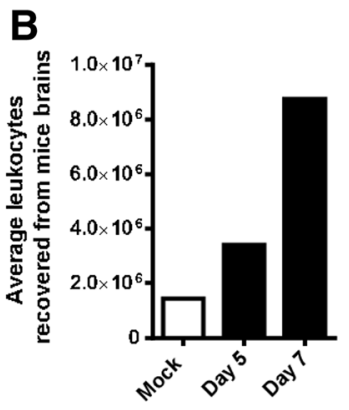

F Activated T CD8 ${ }^{+}$

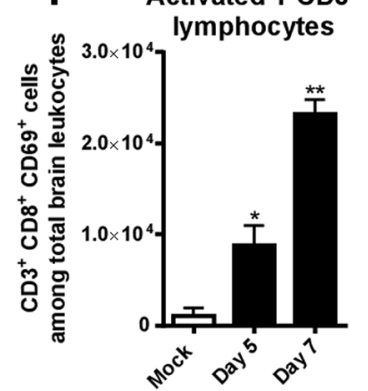

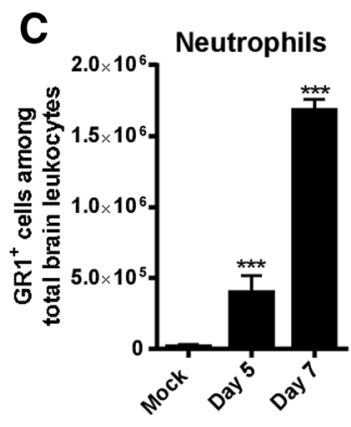

G

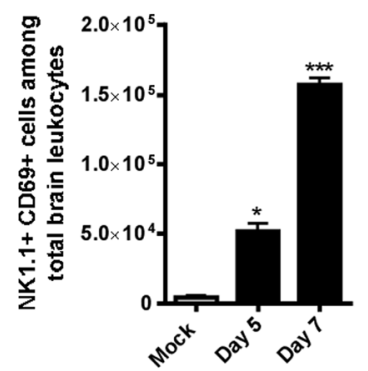

D Macrophages/ Microglia

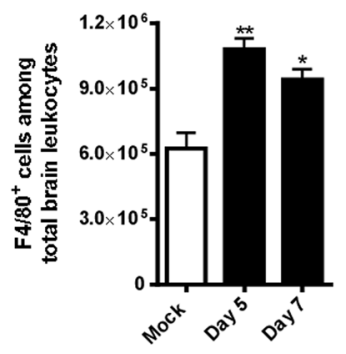

H

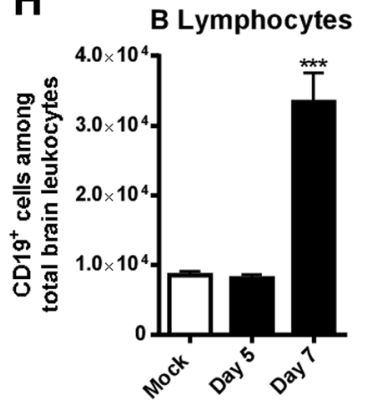

Fig. 5 Neutrophils, T lymphocytes, and NK cells are recruited to the brain of SLEV-infected mice. Adult female C57BL/6 mice were inoculated i.c. with 1 $L_{100}$ of SLEV and euthanized at days 5 and 7 p.i. for collection of brains and extraction of leukocytes. a Representative image of Diff-Quik-stained leukocytes recovered from the brains of SLEV-infected mice. $\mathbf{b}$ Average number of leukocytes recovered from mock and SLEV-infected mice. c-h Recovered leukocytes were stained with antibodies against leukocyte surface markers and analyzed at a flow cytometer. Results are expressed as mean plus standard error of the mean (SEM) and are representative of one experiment $(N=3-6)$. ${ }^{*} P<0.05,{ }^{* *} P<0.01$, ${ }^{* * *} P<0.001$ compared to the respective Mock-infected group. Mock $=$ injected with saline 
population in SLEV infected brains, with an average of 1.5 million cells recruited at day 7 p.i. (Fig. 5c). Macrophages and microglia were both evaluated according to the expression of F4/80 and found to be increased in SLEVinfected groups, although mock-infected mice present a significant amount of F4/80 ${ }^{+}$tissue-resident cells (Fig. 5d). Activated $\mathrm{T} \mathrm{CD}^{+}$(Fig. 5e) and $\mathrm{T} \mathrm{CD} 8^{+}$lymphocytes (Fig. 5f) were increased in the brains of infected mice at both days 5 and 7 p.i., reaching peak numbers at day 7 p.i.. Activated NK cells were also present in infected brains and also peaked at day 7 after infection (Fig. 5g). B lymphocytes were increased in the brains of infected mice only at day 7 p.i. (Fig. 5h). Mock-injected mice showed no evidence of leukocyte recruitment above basal levels.

Altogether, data presented in this section indicate that SLEV infection leads to lymphopenia and to significant leukocyte recruitment to the brain, composed of neutrophils and lymphocytes. Leukocyte recruitment in SLEV experimental infection follows chemokine production and viral replication.

\section{SLEV infection does not affect the spleen and does not cause systemic production of cytokines}

Next, we examine whether i.c. SLEV infection would also induce systemic inflammation, as it inflamed the brain. Spleen and sera were collected from SLEVinfected and mock-infected mice at different time points p.i. and assessed for viral load and or signs of inflammation (Additional file 3: Figure S3). Spleens of both mock and SLEV-infected mice were negative for SLEV, as assessed by plaque assay (Additional file 3: Figure S3A), and showed no evidence for neutrophil or macrophage recruitment, as measured by the activity of MPO and NAG in tissue samples, respectively (Additional file 3: Figure S3B, C). Levels of CCL5, TNF $\alpha$, and IFN $\gamma$, which are increased in the brains of infected mice, were similar between infected and non-infected mice (mock) in the spleen (Additional file 3: Figure S3D, E, F). Accordingly, CCL5, $\mathrm{TNF} \alpha$, and IFN $\gamma$ could not be detected in the sera infected or non-infected mice throughout the evaluated time points (Additional file 3: Figure S3G, H, I). In summary, we found no evidence suggesting that SLEV i.c. infection becomes systemic in this model or induces systemic inflammation.

\section{SLEV infection causes CNS tissue damage and results in behavioral alterations}

Because i.c. SLEV infection in mice caused brain inflammation and because human infection with SLEV is associated with significant morbidity, we assessed whether SLEV infection induced brain damage and/or functional alterations. Our results showed that SLEV causes progressive pathological alterations in the mouse brain, as compared to normal saline-injected brains (Fig. 6a, b). On day 3 , a discrete sign of meningitis is observed (Fig. 6c, asterisk), which evolves to severe meningoencephalitis at days 5 (Fig. 6e) and 7 p.i. (Fig. 6g). The hippocampus was progressively damaged by SLEV infection throughout the evaluated time points (Fig. 6d, f, h, arrows), which may be associated with neuronal death, and presented infiltrating leukocytes at day 7 p.i. (Fig. 6h, asterisk). At day 7 p.i., microgliosis is observed in both cortex and hippocampus (Fig. 6g, h). Histological slides generated in the experiment were also subjected to semi-quantitative analysis (Additional file 4: Figure S4). Our data show that SLEV-infected mice present alterations consistent with meningitis and with damage to the cerebrum and hippocampus (Additional file 4: Figure S4A, B, C). In addition, we found that SLEV infection also caused significant alterations in the brainstem (Additional file 4: Figure S4D).

In order to characterize the behavioral alterations caused by SLEV infection, we used the SHIRPA battery of tests and the open-field test (Fig. 7). For the SHIRPA test, mock-infected and SLEV-infected mice at day 6 p.i. were subjected to a series of quick tests, to measure aspects of murine neurological function. The time point chosen (day 6 p.i.) is due to the fact that infected mice at day 7 p.i. are mostly incapacitated and thus, not able to perform any tests. Our results showed that SLEVinfected mice present a reduction in neuropsychiatric (Fig. 7a) and motor function (Fig. 7b) scores when compared to mock-infected mice, indicating that these neurological functions are affected by SLEV infection.

The open-field test measures the spontaneous movement of a mouse in a defined area. For this experiment, groups of mice were inoculated with saline (Mock), 1 $\mathrm{LD}_{100}$ or $1 \mathrm{LD}_{50}$ of SLEV i.c., to compare mice that receive lethal or sublethal inocula of SLEV, and to study mice that survive the infection among those receiving a sublethal inoculum. We observed that at day 6 p.i., mice from control and infected groups traveled similar distances (Fig. 7c), indicating that these mice had the same rate of spontaneous movement. At day 12 p.i., 4-5 days after the onset of severe disease/mortality, surviving mice present reduced spontaneous movement, as observed by reduction in the distances traveled during the open-field test in comparison to the mock control group (Fig. 7d).

In summary, we observed that SLEV i.c. infection causes progressive brain damage in mice, likely including neuronal loss, that is characterized by meningoencephalitis. The extent of tissue damage correlates SLEV load and inflammation, suggesting that these processes are associated. The onset of experimental St. Louis encephalitis is preceded and followed by neurological alterations, especially in motor function.

\section{SLEV is pathogenic to neurons and glial cells in vitro}

In order to identify the main cell types infected by SLEV, we performed a series of in vitro infections of cells 


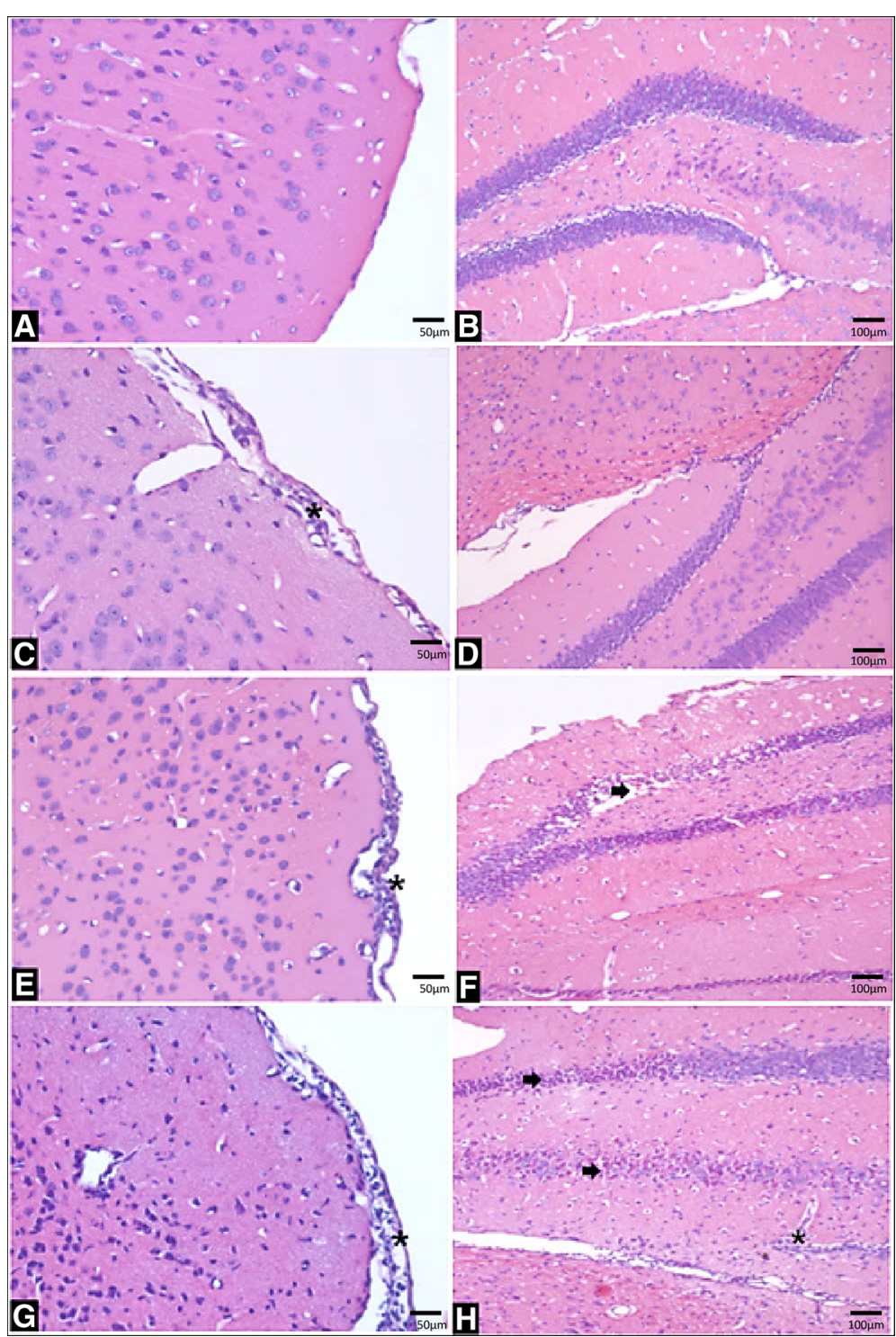

Fig. 6 SLEV infection causes brain damage in mice. Adult female C57BL/6 mice were inoculated i.c. with 1 LD 100 of SLEV and euthanized at days 3, 5, and 7 p.i. for perfusion and collection of brains. Histological sections were stained in H\&E and analyzed under an optical microscope. Images of the cerebral cortex/meninges are shown on the left $(\mathbf{a}, \mathbf{c}, \mathbf{e}, \mathbf{g})$ (magnification $\times 400)$ and the hippocampus on the right $(\mathbf{b}, \mathbf{d}, \mathbf{f}, \mathbf{h})$ (magnification $\times 200$ ). a, b Brain histological sections representative of a Mock-infected mouse, followed by images from infected animals at day 3 $(\mathbf{c}, \mathbf{d})$, day $5(\mathbf{e}, \mathbf{f})$, and day 7 p.i. $(\mathbf{g}, \mathbf{h})$. Images show the development of meningitis (asterisk, $\mathbf{c}, \mathbf{e}, \mathbf{g}$ ) and meningoencephalitis with microgliosis (g). Tissue damage/degeneration (arrows) and (asterisk) inflammation in the hippocampus are observed in (f, $\mathbf{h}) . N=3$ mice per group. Mock $=$ injected with saline

representing the main cell populations present in the CNS: neurons and glia (Fig. 8). The murine neuroblast cell line N1E-115 was first tested and found to be permissive to SLEV infection and replication (Fig. 8a). When infected with SLEV at a multiplicity of infection (MOI) of 0.1, N1E-115 cells released infective SLEV in the culture supernatant at all time points evaluated (24-96 h p.i.), reaching peak levels at $72 \mathrm{~h}$ p.i.. We next performed a primary culture of murine neurons isolated from C57BL/6 mice, which were infected with SLEV at a
MOI of 0.1 and assessed for neuronal death (Fig. 8b). We observed that primary murine neurons are very susceptible to SLEV infection, as SLEV-infected cultures presented $50 \%$ cell death already at 24 h p.i.. Neuronal death increased to $80 \%$ at 48 and $72 \mathrm{~h}$ p.i. and resulted in complete death at $96 \mathrm{~h}$ p.i., when compared to mockinfected controls, which received culture medium.

Primary glial cultures were obtained from newborn C57BL/6 mice and consisted in a confluent mixed culture of astrocytes, oligodendrocytes, and microglia. 

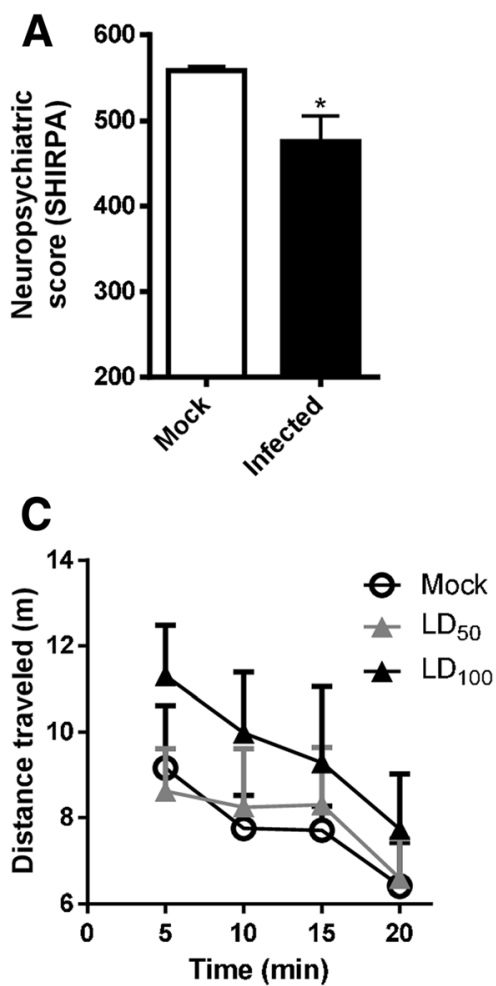
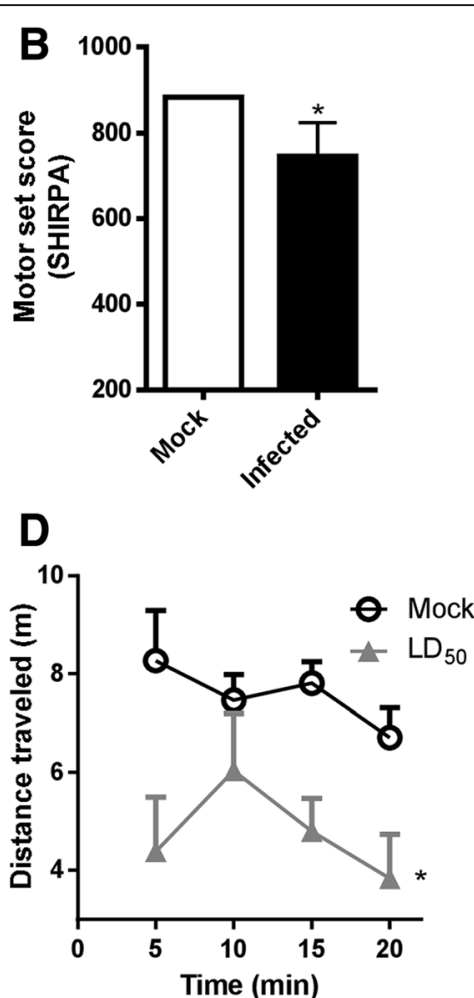

Fig. 7 SLEV infection causes neurological alterations in mice. Adult female C57BL/6 mice were inoculated with SLEV or saline i.c. and tested at days 6 or 12 p.i. for neurological alterations. $\mathbf{a}$, b Mice inoculated with 1LD 100 of SLEV or saline were submitted to the SHIRPA battery of tests at day 6 p.i., to evaluate neurological scores on neuropsychiatric (a) and motor functions (b). c, d Mice inoculated with 1 LD 100 , $1 \mathrm{LD}_{50}$, or saline were submitted to the open field test to evaluate mice spontaneous locomotor activity at day 6 or 12 p.i., through measurement of the distance traveled in a defined area for 20 min. Results are expressed as mean plus SEM and are representative of two experiments $(N=7-8)$. Mock $=$ injected with saline

Cultures were again infected with SLEV at a MOI of 0.1 and maintained for up to $120 \mathrm{~h}$ for supernatant collection (Fig. 8c, d). Samples were assessed for their viral content and results showed that SLEV replicates in glial cells, reaching peak levels in cultures at $72 \mathrm{~h}$ p.i. (Fig. $8 \mathrm{c}$ ). SLEV replication was associated to the release of proinflammatory cytokines in the culture supernatant (Fig. 8d-g). Cytokines CCL5, IL-6, and CXCL1 were detected in glia culture supernatants and increased along the time points evaluated in SLEV-infected cultures. CCL5 was detected earlier in glial cultures, increasing in infected cultures at $48 \mathrm{~h}$ p.i. in comparison to Mock, and increasing further at 72, 96, and $120 \mathrm{~h}$ p.i. (Fig. 8d). IL-6 was increased in cell cultures at 72 and $96 \mathrm{~h}$ p.i. and reached peak levels at $120 \mathrm{~h}$ p.i. (Fig. 8f). CXCL1 was increased in comparison to Mock controls only at 120 h p.i. (Fig. 8g). Notably, IFNy (Fig. 8e) was not detected in control or SLEV-infected cultures at any of the evaluated time points.

In conclusion, we suggest that SLEV is able to infect and replicate in cultures of both neuronal and glial cells of mice. In vitro SLEV infection is pathogenic, capable of inducing neuronal cell death and cytokine release by glial cells, which correlates with SLEV pathogenicity in vivo and suggests that SLEV may interact with more than one cell type in the brain.

\section{Discussion}

In this manuscript, we presented a robust model of St. Louis encephalitis in mice, characterized by viral replication, inflammation, brain damage, neurological alterations, and death. Importantly, these are main characteristics of severe disease caused by SLEV in humans [13, 18, 30, 34] that are reproduced in this experimental model. In addition, the observation that SLEV infects and replicates in murine neuronal cells correlates with the presence of SLEV in human neurons [35].

Up to now, mouse models of St. Louis encephalitis have focused on infection indices and mortality rates $[25,26,28]$ and lacked insights into the contribution of inflammation to severe disease pathogenesis. Inflammation is a major feature of flaviviral disease, as extensively demonstrated for dengue, West Nile, and Japanese encephalitis [36-41]. In our model, the majority of disease parameters evaluated reach peak levels at day 7 p.i. and immediately preceded the manifestation of severe disease and death. Altogether, we suggest that day 7 p.i. is the peak of infection/disease in this model. 


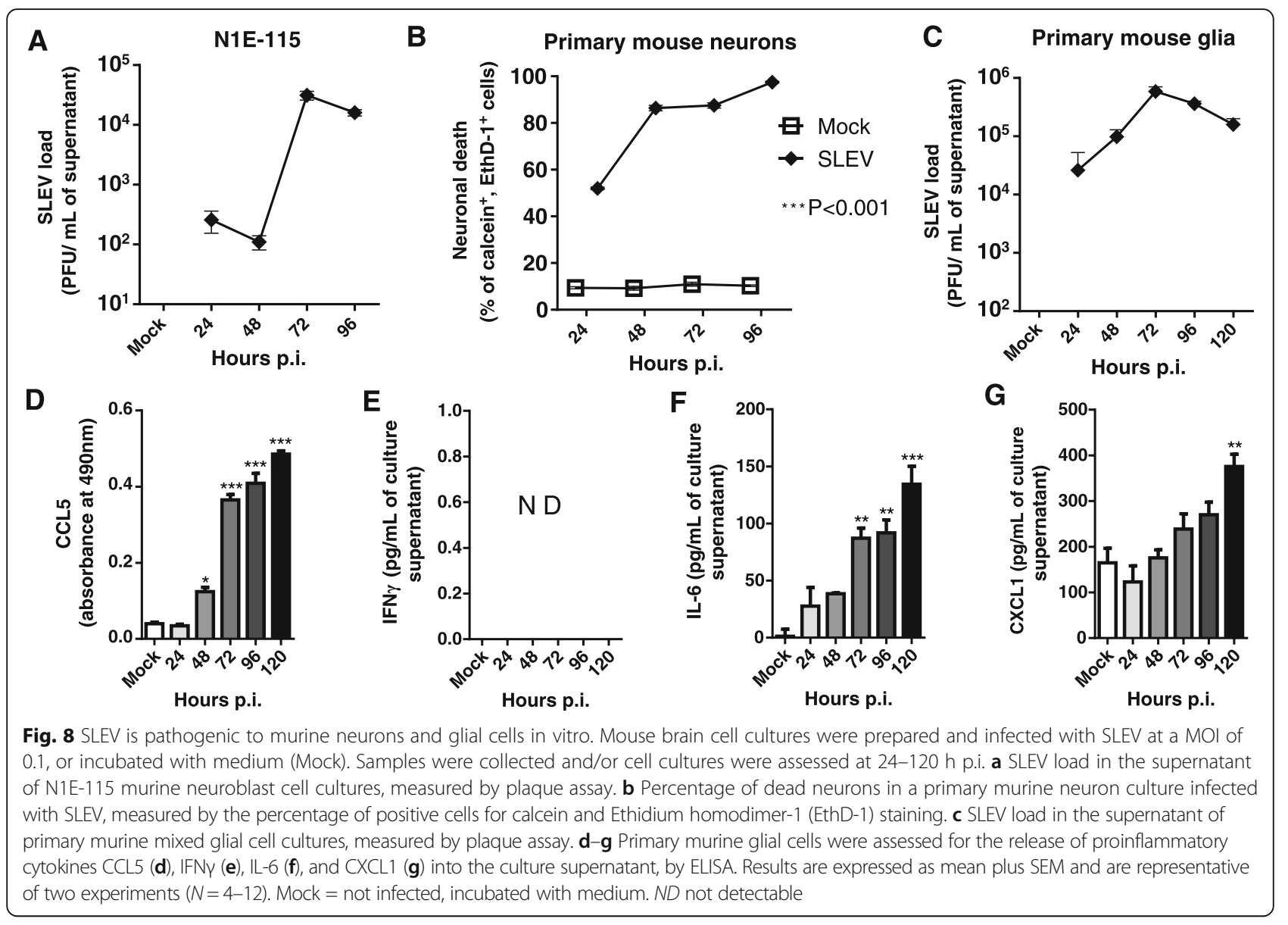

The SLEV strain BeH 355964 was chosen to establish this in vivo model because of key features: SLEV BeH 355964 was originally isolated from a symptomatic patient in Brazil [30], and thus it is associated to disease occurrence in humans; SLEV BeH 355964 is a reference SLEV strain used for research purposes [11, 31, 42, 43], and its entire genome sequence was recently published [5]. Also, adult immunocompetent mice were chosen because their immune and inflammatory responses are intact, contrary to the biased response of knockout or young mice, which are known to be more susceptible to other routes of virus inoculation [15, 25, 27, 44]. Thus, we designed our experimental SLEV model to prioritize the study of the host immunological response to a clinically relevant virus isolate. Unfortunately, our model was limited by the fact that $\mathrm{BeH} 355964$ was unable to cause disease in adult immunocompetent mice when injected peripherally. By injecting virus i.c., we skip initial phases of infection at the skin and lymphoid tissues, which are believed to precede flavivirus invasion of the CNS [45]. Therefore, we consider our animal model to better represent SLEV-induced severe disease, where SLEV has already invaded the CNS, and causes meningoencephalitis.
We observed by different techniques that i.c. SLEV inoculation in mice results in acute brain inflammation, corroborating previous reports $[22,24]$. We suggest that SLEV replication in the brain triggers the local production of proinflammatory cytokines that ultimately causes SLEVinduced meningoencephalitis. We have performed preliminary experiments using mice deficient in the plateletactivating factor receptor $\left(\mathrm{PAFR}^{-1-}\right)$ or deficient in the complement $\mathrm{C} 5 \mathrm{a}$ receptor $\left(\mathrm{C}^{\mathrm{a} \mathrm{R}^{-/-}}\right)$and found that these molecules were not involved in the pathogenesis of experimental St. Louis encephalitis. Among the cytokines evaluated in this study, the chemokines CCL5 and CXCL1 (Fig. 3) are known to mediate the recruitment of lymphocytes [46] and neutrophils [47] and are likely to mediate the infiltration these leukocyte populations into the SLEVinfected brain [45]. Clinical or post mortem studies in individuals diagnosed with St. Louis encephalitis frequently showed meningitis associated with lymphocytic and granulocytic infiltration, as well as pleocytosis $[13,34,48]$. The observation that glial cells are activated during SLEV infection and release proinflammatory cytokines in vitro (shown in Fig. 8) is suggestive that these cells may initiate the inflammatory response to SLEV in vivo [43]. Moreover, we observed an increase in a $\mathrm{F} 4 / 80^{+}$population, presumably 
microglia, and identified microgliosis in histological analysis of SLEV-infected brains which support the involvement of microglia in the infection.

IFNY was not expressed by SLEV-infected glial cells in vitro. However, IFN $\gamma$ levels increase in mice brains at the peak of SLEV infection, together with cytokines that were found to be produced by glia, such as CCL5 and IL-6. We suggest that recruited leukocyte populations could be source of IFN $\gamma$ in vivo, most likely NK and T lymphocytes. These lymphocyte populations are activated and abundant in the brains of infected mice at day 7 p.i. and are known to produce IFN $\gamma$ in response to flaviviral infection [49]. Moreover, IFNY was pathogenic in a murine model of Japanese encephalitis by causing blood-brain barrier disruption [40]. The correlation of IFNY expression in SLEV-infected brains and the onset of severe neurological disease and mortality indicate that IFNY could be involved in the pathogenesis of experimental St. Louis encephalitis, but this contention clearly deserves further experimentation.

\section{Conclusions}

The association of SLEV infection with a major inflammatory response in the brain, and to severe neurological damage and dysfunction, suggests that inflammation plays a major role in St. Louis encephalitis pathogenesis. More studies are necessary to fully elucidate the mechanisms by which SLEV causes this pathogenic host response to infection in the CNS, resulting in tissue damage and in death. We suggest that therapeutic strategies to reduce CNS inflammation may be beneficial in the context of St. Louis encephalitis.

\section{Additional files}

Additional file 1: Figure S1. Adult immunocompetent mice are resistant to SLEV when inoculated through peripheral routes. Eight- to 12-week-old female C57BL/6 mice were inoculated with $10^{3}$ PFU of SLEV BeH 355964 through different routes (intraperitoneal, intraplantar, subcutaneous, and intracranial) and observed for 14 days post infection. Results are expressed as percentage of survival in each group and is representative of one experiment. $N=5$ mice. (TIF $40 \mathrm{~kb}$ )

Additional file 2: Figure S2. Experimental SLEV infection does not change platelet counts or the hematocrit index. Adult female C57BL/6 mice were inoculated i.c. with $1 \mathrm{LD}_{100}$ of SLEV and euthanized at days 3, 5, and 7 p.i. for blood collection. Platelet counts (A) and the hematocrit index (B) were quantified in heparinized samples. Results are expressed as mean plus SEM and are representative of one experiment $(N=3-8)$. Mock = injected with saline. (TIFF $120 \mathrm{~kb}$ )

Additional file 3: Figure S3. Intracranial SLEV infection does not affect the spleen or causes systemic inflammation. Adult female C57BL/6 mice were inoculated i.c. with $1 \mathrm{LD}_{100}$ of SLEV and euthanized at days 3, 5, and 7 p.i. for collection of spleens and sera. Spleen samples were processed and assessed for SLEV load (A) by plaque assay and enzymatic activity of MPO (B) and NAG (C). Levels of the cytokines CCL5, TNFa, and IFNY were measured in spleen $(D, E, F)$ and serum samples $(G, H, I)$. Results are expressed as dot plot or mean plus SEM and are representative of two experiments $(N=6-12)$. Mock $=$ injected with saline. $\mathrm{ND}=$ not detectable. (TIFF $360 \mathrm{~kb}$ )
Additional file 4: Figure S4. Histopathological alterations in SLEV-infected mice are quantifiable in the meninges, brain, hippocampus, and brainstem. Adult female C57BL/6 mice were inoculated i.c. with $1 \mathrm{LD}_{100}$ of SLEV and euthanized at days 3, 5, and 7 p.i. for collection of brains for a histological semi-quantitative analysis. Slides were scored on up to four points, with four corresponding to maximum tissue damage. Scores were set based on the histological aspect of samples from the mock-infected group. Brain regions analyzed included the meninges (A), the cerebrum (B), the hippocampus (C) and the brainstem (D). Results are expressed as dot-plot and the median for each experiment group. ${ }^{*} P<0.05,{ }^{* *} P<0.01$ compared to the respective day 3 p.i. group. Mock = injected with saline. (TIFF $122 \mathrm{~kb})$

\section{Abbreviations}

ANOVA: Analysis of variance; CEUA: Internal committee of ethics on animal. use; CNS: Central nervous system; EPO: Eosinophil peroxydase; FBS: Fetal bovine serum; i.c.: Intracranial; i.p.: Intraperitoneal; IFN: Interferon; JEV: Japanese encephalitis virus; $L_{50 / 100}$ : Lethal dose for $50 \% / 100 \%$ subjects; MOl: Multiplicity of infection; MPO: Mieloperoxydase; NAG: N-Acetyl-ß-D-glucosaminidase; p.i.: Post infection; PFU: Plaque forming units; RT-qPCR: Reverse transcriptase quantitative PCR; SEM: Standard error of the mean; SHIRPA: SmithKline Beecham, Harwell, Imperial College, Royal London Hospital, phenotype assessment; SLEV: St. Louis encephalitis virus; St:: Saint; UFMG: Universidade Federal de Minas Gerais; WNV: West Nile virus; WT: Wild type; ZIKV: Zika virus

\section{Acknowledgements}

We thank Fátima Brant for providing us with the methods for the flow cytometry and mixed glia experiments. We thank professor Flávio Amaral for his continuous support. We also thank IIma Marçal for her assistance in the logistic aspects of research.

\section{Funding}

This work was supported by Instituto Nacional de Ciência e Tecnologia (INCT) em Dengue, Conselho Nacional de Desenvolvimento Cientifico e Tecnológico (CNPq), Fundação de Amparo à Pesquisa do Estado de Minas Gerais (FAPEMIG), and Coordenação de Aperfeiçoamento de Pessoal de Nível Superior (CAPES). MLN was supported by a grant (2013/21719-3) from Fundação de Amparo à Pesquisa do Estado de São Paulo (FAPESP).

\section{Availability of data and materials}

All data generated or analyzed during this study are included in this published article [and its supplementary information files].

\section{Authors' contributions}

REM, MLN, and MMT conceived the study. REM, JLDS, RFR, GFG, and AC performed the experiments. MAR processed and analyzed histological samples. DGS, MLN, and MMT provided necessary infrastructure and consumables. REM and MMT wrote the paper. All authors read and approved the final manuscript.

\section{Competing interests}

The authors declare that they have no competing interests.

\section{Consent for publication}

Not applicable.

\section{Ethics approval}

All experimental procedures were approved by and complied with the regulations of Universidade Federal de Minas Gerais (UFMG) Committee for Ethics in Animal Use (CEUA), under protocol number 349/2012.

\section{Publisher's Note}

Springer Nature remains neutral with regard to jurisdictional claims in published maps and institutional affiliations.

\section{Author details}

'Immunopharmacology, Departamento de Bioquímica e Imunologia, Instituto de Ciências Biológicas, Universidade Federal de Minas Gerais, Belo Horizonte, Minas Gerais, Brazil. ${ }^{2}$ Laboratório de Investigação em Neurodegeneração e Infecção, Hospital Universitário João de Barros Barreto, Universidade Federal do Pará, Belém, Pará, Brazil. ${ }^{3}$ Laboratório de 
Imunorregulação de Doenças Infecciosas, Departamento de Bioquímica e Imunologia, Instituto de Ciências Biológicas, Universidade Federal de Minas Gerais, Belo Horizonte, Minas Gerais, Brazil. ${ }^{4}$ Laboratório de Apoptose, Departamento de Patologia Geral, Instituto de Ciências Biológicas, Universidade Federal de Minas Gerais, Belo Horizonte, Minas Gerais, Brazil. ${ }^{5}$ Laboratório de Interação Microrganismo-Hospedeiro, Departamento de Microbiologia, Instituto de Ciências Biológicas, Universidade Federal de Minas Gerais, Belo Horizonte, Minas Gerais, Brazil. 'aboratório de Pesquisas em Virologia, Departamento de Doenças dermatológicas, Infecciosas e Parasitárias, Faculdade de Medicina de São José do Rio Preto, São José do Rio Preto, São Paulo, Brazil. ${ }^{7}$ Present address: Laboratório Nacional de Biociências, Centro Nacional de Pesquisa em Energia e Materiais, Campinas, São Paulo, Brazil.

\section{Received: 23 September 2016 Accepted: 9 March 2017} Published online: 22 March 2017

\section{References}

1. Diaz LA, Albrieu Llinas G, Vazquez A, Tenorio A, Contigiani MS. Silent circulation of St. Louis encephalitis virus prior to an encephalitis outbreak in Cordoba, Argentina (2005). PLoS Negl Trop Dis. 2012;6:e1489.

2. Venkat H, Krow-Lucal E, Hennessey M, Jones J, Adams L, Fischer M, Sylvester T, Levy C, Smith K, Plante L, et al. Concurrent outbreaks of St. Louis encephalitis virus and West Nile virus disease-Arizona, 2015. MMWR Morb Mortal Wkly Rep. 2015;64:1349-50.

3. Rosa R, Costa EA, Marques RE, Oliveira TS, Furtini R, Bomfim MR, Teixeira MM, Paixao TA, Santos RL. Isolation of saint louis encephalitis virus from a horse with neurological disease in Brazil. PLoS Negl Trop Dis. 2013;7:e2537.

4. Baillie GJ, Kolokotronis SO, Waltari E, Maffei JG, Kramer LD, Perkins SL. Phylogenetic and evolutionary analyses of St. Louis encephalitis virus genomes. Mol Phylogenet Evol. 2008;47:717-28.

5. Vedovello D, Drumond BP, Marques RE, Ullmann LS, Favaro EA, Terzian AC, Figueiredo LT, Teixeira MM, Junior JP, Nogueira ML. First genome sequence of St. Louis encephalitis virus (SLEV) isolated from a human in Brazil. Arch Virol. 2015;160:1189-95.

6. Kopp A, Gillespie TR, Hobelsberger D, Estrada A, Harper JM, Miller RA, Eckerle I, Muller MA, Podsiadlowski L, Leendertz FH, et al. Provenance and geographic spread of St. Louis encephalitis virus. MBio. 2013;4:e00322-00313.

7. Tesh RB, Travassos da Rosa AP, Guzman H, Araujo TP, Xiao SY. Immunization with heterologous flaviviruses protective against fatal West Nile encephalitis. Emerg Infect Dis. 2002;8:245-51.

8. Sips GJ, Wilschut J, Smit JM. Neuroinvasive flavivirus infections. Rev Med Virol. 2012;22:69-87.

9. Ribeiro LS, Marques RE, Jesus AM, Almeida RP, Teixeira MM. Zika crisis in Brazil: challenges in research and development. Curr Opin Virol. 2016;18:76-81.

10. Gould EA, Solomon T. Pathogenic flaviviruses. Lancet. 2008;371:500-9.

11. Terzian AC, Mondini A, Bronzoni RV, Drumond BP, Ferro BP, Cabrera EM, Figueiredo LT, Chiaravalloti-Neto F, Nogueira ML. Detection of Saint Louis encephalitis virus in Dengue-suspected cases during a dengue 3 outbreak. Vector Borne Zoonotic Dis. 2011;11:291-300.

12. Mondini A, Cardeal IL, Lazaro E, Nunes SH, Moreira CC, Rahal P, Maia IL, Franco C, Gongora DV, Gongora-Rubio F, et al. Saint Louis encephalitis virus, Brazil. Emerg Infect Dis. 2007;13:176-8.

13. Muckenfuss RS. Clinical observations and laboratory investigations on the 1933 epidemic of encephalitis in St. Louis. Bull N Y Acad Med. 1934;10:444-53.

14. Southern Jr PM, Smith JW, Luby JP, Barnett JA, Sanford JP. Clinical and laboratory features of epidemic St. Louis encephalitis. Ann Intern Med. 1969;71:681-9.

15. Clark DC, Brault AC, Hunsperger E. The contribution of rodent models to the pathological assessment of flaviviral infections of the central nervous system. Arch Virol. 2012;157(8):1423-40.

16. Spinsanti L, Basquiera AL, Bulacio S, Somale V, Kim SC, Re V, Rabbat D, Zarate A, Zlocowski JC, Mayor CQ, et al. St. Louis encephalitis in Argentina: the first case reported in the last seventeen years. Emerg Infect Dis. 2003;9:271-3.

17. Sejvar JJ, Bode AV, Curiel M, Marfin AA. Post-infectious encephalomyelitis associated with St. Louis encephalitis virus infection. Neurology. 2004;63:1719-21.
18. Greve KW, Houston RJ, Adams D, Stanford MS, Bianchini KJ, Clancy A, Rabito Jr FJ. The neurobehavioural consequences of St. Louis encephalitis infection. Brain Inj. 2002;16:917-27.

19. Pugachev KV, Guirakhoo F, Mitchell F, Ocran SW, Parsons M, Johnson BW, Kosoy OL, Lanciotti RS, Roehrig JT, Trent DW, Monath TP. Construction of yellow fever/St. Louis encephalitis chimeric virus and the use of chimeras as a diagnostic tool. Am J Trop Med Hyg. 2004;71:639-45.

20. Venugopal K, Jiang WR, Gould EA. Immunity to St. Louis encephalitis virus by sequential immunization with recombinant vaccinia and baculovirus derived PrM/E proteins. Vaccine. 1995;13:1000-5

21. Phillpotts RJ, Venugopal K, Brooks T. Immunisation with DNA polynucleotides protects mice against lethal challenge with St. Louis encephalitis virus. Arch Virol. 1996;141:743-9.

22. Smadel JE, Moore E. Changes Produced in the Central Nervous System of the Mouse by the Virus of St. Louis Encephalitis. Am J Pathol. 1934;10:827-34. 823.

23. Holbrook MR, Gowen BB. Animal models of highly pathogenic RNA viral infections: encephalitis viruses. Antiviral Res. 2008;78:69-78.

24. Webster LT, Fite GL. A virus encountered in the study of material from cases of encephalitis N the St. Louis and Kansas city epidemics of 1933. Science. 1933;78:463-5.

25. Monath TP, Cropp CB, Bowen GS, Kemp GE, Mitchell CJ, Gardner JJ. Variation in virulence for mice and rhesus monkeys among St. Louis encephalitis virus strains of different origin. Am J Trop Med Hyg. 1980;29:948-62.

26. Phillpotts RJ, Jones LD, Lukaszewski RA, Lawrie C, Brooks TJ. Antibody and interleukin-12 treatment in murine models of encephalitogenic flavivirus (St. Louis encephalitis, tick-borne encephalitis) and alphavirus (Venezuelan equine encephalitis) infection. J Interferon Cytokine Res. 2003;23:47-50.

27. Brooks TJ, Phillpotts RJ. Interferon-alpha protects mice against lethal infection with St Louis encephalitis virus delivered by the aerosol and subcutaneous routes. Antiviral Res. 1999;41:57-64.

28. Monath TP, Cropp CB, Harrison AK. Mode of entry of a neurotropic arbovirus into the central nervous system. Reinvestigation of an old controversy. Lab Invest. 1983;48:399-410.

29. Nalca A, Fellows PF, Whitehouse CA. Vaccines and animal models for arboviral encephalitides. Antiviral Res. 2003;60:153-74.

30. Pinheiro FP, LeDuc JW, da Rosa AP T, Leite OF. Isolation of St. Louis encephalitis virus from a patient in Belem, Brazil. Am J Trop Med Hyg. 1981;30:145-8.

31. de Morais Bronzoni RV, Baleotti FG, Ribeiro Nogueira RM, Nunes M, Moraes Figueiredo LT. Duplex reverse transcription-PCR followed by nested PCR assays for detection and identification of Brazilian alphaviruses and flaviviruses. J Clin Microbiol. 2005;43:696-702.

32. Marques RE, Guabiraba R, Del Sarto JL, Rocha RF, Queiroz AL, Cisalpino D, Marques PE, Pacca CC, Fagundes CT, Menezes GB, et al. Dengue virus requires the $\mathrm{CC}$-chemokine receptor CCR5 for replication and infection development. Immunology. 2015;145:583-96.

33. Rogers DC, Fisher EM, Brown SD, Peters J, Hunter AJ, Martin JE. Behavioral and functional analysis of mouse phenotype: SHIRPA, a proposed protocol for comprehensive phenotype assessment. Mamm Genome. 1997;8:711-3.

34. Cerna F, Mehrad B, Luby JP, Burns D, Fleckenstein JL. St. Louis encephalitis and the substantia nigra: MR imaging evaluation. AJNR Am J Neuroradiol. 1999;20:1281-3.

35. Reyes MG, Gardner JJ, Poland JD, Monath TP. St Louis encephalitis. Quantitative histologic and immunofluorescent studies. Arch Neurol. 1981;38:329-34

36. Marques RE, Guabiraba R, Cisalpino D, Teixeira MM, Souza DG. Dengue. Colloquium Series on Integrated Systems Physiology: From Molecule to Function. 2014;6:1-104.

37. Souza DG, Fagundes CT, Sousa LP, Amaral FA, Souza RS, Souza AL, Kroon EG, Sachs D, Cunha FQ, Bukin E, et al. Essential role of platelet-activating factor receptor in the pathogenesis of Dengue virus infection. Proc Natl Acad Sci U S A. 2009;106:14138-43.

38. Guabiraba R, Besnard AG, Marques RE, Maillet I, Fagundes CT, Conceicao TM, Rust NM, Charreau S, Paris I, Lecron JC, et al. IL-22 modulates IL-17A production and controls inflammation and tissue damage in experimental dengue infection. Eur J Immunol. 2013:43:1529-44.

39. Guabiraba R, Marques RE, Besnard AG, Fagundes CT, Souza DG, Ryffel B, Teixeira MM. Role of the chemokine receptors CCR1, CCR2 and CCR4 in 
the pathogenesis of experimental dengue infection in mice. PLoS One. 2010;5:e15680.

40. Li F, Wang Y, Yu L, Cao S, Wang K, Yuan J, Wang C, Cui M, Fu ZF. Viral infection of the central nervous system and neuroinflammation precede blood-brain barrier disruption during Japanese encephalitis virus infection. J Virol. 2015;89:5602-14.

41. de Wispelaere M, Frenkiel MP, Despres P. A Japanese encephalitis virus genotype 5 molecular clone is highly neuropathogenic in a mouse model: impact of the structural protein region on virulence. J Virol. 2015;89:5862-75.

42. Re V, Spinsanti L, Farias A, Diaz A, Vazquez A, Aguilar J, Tenorio A, Contigiani M. Reliable detection of St. Louis encephalitis virus by RT-nested PCR. Enferm Infecc Microbiol Clin. 2008;26:10-5.

43. Zuza AL, Barros HL, de Mattos Silva Oliveira TF, Chavez-Pavoni JH, Zanon RG. Astrocyte response to St. Louis encephalitis virus. Virus Res. 2016;217:92-100.

44. Harrison AK, Murphy FA, Gardner JJ. Visceral target organs in systemic St. Louis encephalitis virus infection of hamsters. Exp Mol Pathol. 1982;37:292-304.

45. Bardina SV, Lim JK. The role of chemokines in the pathogenesis of neurotropic flaviviruses. Immunol Res. 2012;54:121-32.

46. Marques RE, Guabiraba R, Russo RC, Teixeira MM. Targeting CCL5 in inflammation. Expert Opin Ther Targets. 2013;17:1439-60.

47. Russo RC, Guabiraba R, Garcia CC, Barcelos LS, Roffe E, Souza AL, Amaral FA, Cisalpino D, Cassali GD, Doni A, et al. Role of the chemokine receptor CXCR2 in bleomycin-induced pulmonary inflammation and fibrosis. Am J Respir Cell Mol Biol. 2009;40:410-21.

48. Wasay M, Diaz-Arrastia R, Suss RA, Kojan S, Haq A, Burns D, Van Ness P. St Louis encephalitis: a review of 11 cases in a 1995 Dallas, Tex, epidemic. Arch Neurol. 2000;57:114-8.

49. Fagundes CT, Costa W, Cisalpino D, Amaral FA, Souza PR, Souza RS, Ryffel B, Vieira LQ, Silva TA, Atrasheuskaya A, et al. IFN-gamma production depends on IL-12 and IL-18 combined action and mediates host resistance to dengue virus infection in a nitric oxide-dependent manner. PLoS Negl Trop Dis. 2011;5:e1449.

\section{Submit your next manuscript to BioMed Central and we will help you at every step:}

- We accept pre-submission inquiries

- Our selector tool helps you to find the most relevant journal

- We provide round the clock customer support

- Convenient online submission

- Thorough peer review

- Inclusion in PubMed and all major indexing services

- Maximum visibility for your research

Submit your manuscript at www.biomedcentral.com/submit 